\title{
Use of Steel Slag as Coarse Aggregate for the Production of Pervious Concrete
}

\author{
Georgia Vardaka ${ }^{* 1}$, Kiriakos Thomaidis ${ }^{1}$, Christos Leptokaridis ${ }^{2}$, Stamatis Tsimas $^{1}$ \\ ${ }^{1}$ School of Chemical Engineering, \\ National Technical University of Athens, Greece \\ e-mail: georgiavar@gmail.com \\ ${ }^{2}$ TITAN Cement Company S.A., \\ Group R and D, Greece
}

Cite as: Vardaka, G., Thomaidis, K., Leptokaridis, C., Tsimas, S., Use of Steel Slag as Coarse Aggregate for the Production of Pervious Concrete, J. sustain. dev. energy water environ. syst., 2(1), pp 30-40, 2014, DOI: http://dx.doi.org/10.13044/j.sdewes.2014.02.0003

\begin{abstract}
Pervious concrete is a type of concrete with significantly increased water permeability, ensuring increased rates of drainage of rainfall. The high porosity is achieved by removing a large percentage of fine aggregates from the mix. The present paper is an approach for the addition of steel slag as a substitute for coarse aggregates in pervious concrete. More specifically, three types of aggregates have been used: steel slag, construction and demolition wastes and conventional limestone aggregates. The produced pervious concretes are compared for their properties, such as water permeability, compressive strength and abrasion behaviour. Also this paper contains the study of the porosity analysis of these pervious concrete mix designs by using porosity profiles produced from X-ray CT Scanning. According to the results of this paper, it is observed that the incorporation of industry by-products or of Construction and Demolition (C\&D) wastes leads to better abrasion behaviour, and to the increase, in some cases, of the compressive strength and of the water permeability.
\end{abstract}

\section{KEYWORDS}

Pervious concrete, Steel slag, Construction and demolition wastes, Alternative aggregates, Water permeability, Porosity analysis

\section{INTRODUCTION}

Construction has a large environmental impact and there is increased awareness of its effects. A typical example of this is the reduction of the absorption capacity of surface land due to continuous building construction which results in insufficient flood protection and aquifer replenishment. Our research aim should be to protect the environment while facing the problems arising from human activity. This is shown from recent trends in research, including in the concrete and cement industry, for the development of reasonable rainwater management. The beginning of these efforts has started in the last decade in the U.S.A. with the design and development of a new type of product: pervious concrete.

Pervious concrete pavement is a unique and effective means to address important environmental issues and support green, sustainable growth. By capturing storm water and allowing it to seep into the ground, pervious concrete is instrumental in recharging groundwater and reducing storm water runoff $[1-3,11,12]$.

In pervious concrete, carefully controlled amounts of water and cementitious materials are used to create a paste that forms a thick coating around aggregate particles. A pervious

${ }^{*}$ Corresponding author 
concrete mixture contains little or no sand, creating a substantial void content. Using sufficient paste to coat and bind the aggregate particles together creates a system of highly permeable, interconnected voids that drains quickly. Typically, between $15 \%$ and $25 \%$ voids are achieved in the hardened concrete, and flow rates for water through pervious concrete are typically around $0.34 \mathrm{~cm} / \mathrm{s}$, (or $200 \mathrm{~L} / \mathrm{m}^{2} / \mathrm{min}$ ), although they can be much higher. Both the low mortar content and high porosity also reduce strength compared to conventional concrete mixtures, but sufficient strength for many applications can be achieved $[1,2,4,5]$.

Pervious concrete has been used in a wide range of applications, including: Pervious pavement for parking lots, rigid drainage layers under exterior mall areas, greenhouse floors to keep the floor free from standing water, structural wall applications where lightweight or better thermal insulation characteristics, or even both, are required, pavements, walls, and floors where better acoustic absorption characteristics are desired, etc. [1,2].

In this paper, in the frame of a related $\mathrm{PhD}$ thesis, an approach to the addition of steel slag and of construction and demolition wastes as substitutes for coarse aggregates in pervious concrete is examined. The reuse of these materials will reduce the need for landfilling and it will constitute yet another alternative solution for their management [6].

A lot of research work has been done with the use of steel slag and of C\&D Wastes as aggregates for new concrete production. The common reference point of all these research efforts is that the concrete containing C\&D Wastes can be used in secondary applications since its quality is inferior to commonly produced concrete. Recycled Concrete Aggregates (RCA), as used in Results and Discussion, present a high porosity which, for the production of the conventional type of concrete, constitutes a disadvantage. However, for the production of pervious concrete, high porosity is the main desired quality. [6-9, 11] Also previous research papers show that the use of steel slag as aggregate for the production of non-reinforced concrete increases the compressive strength $[10,11]$

\section{MATERIALS AND METHODS}

The scope of the present paper is the exploitation of selected Steel Slag and of Construction and Demolition (C\&D) wastes as substitutes for the conventional aggregates that are used in the concrete industry. Three types of aggregates have been used: steel slag, construction and demolition wastes and conventional limestone aggregates. These aggregates have been previously characterized by means of their chemical analyses, their granulometry as well their analysis in $\mathrm{N}_{2}$ porosimeter. The produced samples of pervious concrete are compared for their basic properties such as water permeability, compressive strength, percentage of void content and abrasion behaviour.

\section{Chemical Analysis}

Table 1. Chemical Compositions in \% of Steel Slag, Limestone Aggregates and C\&D Wastes

\begin{tabular}{cccc}
\hline Element oxide & Steel Slag & Limestone Aggregates & Construction and Demolition Wastes \\
\hline $\mathrm{CaO}$ & 41.33 & 52.8 & 44.7 \\
$\mathrm{SiO}_{2}$ & 14.92 & 1.16 & 20.1 \\
$\mathrm{Al}_{2} \mathrm{O}_{3}$ & 7.22 & 0.67 & 4.72 \\
$\mathrm{Fe}_{2} \mathrm{O}_{3}$ & 22.62 & 0.33 & 1.79 \\
$\mathrm{SO}_{3}$ & 0.29 & $<0.01$ & 0.04 \\
$\mathrm{MgO}$ & 1.91 & 0.89 & 0.69 \\
$\mathrm{~K}_{2} \mathrm{O}$ & 0.01 & $<0.01$ & 0.5 \\
$\mathrm{Na}_{2} \mathrm{O}$ & 0.19 & 0 & 0.4 \\
$\mathrm{Cl}^{-}$ & 0.01 & $<0.01$ & 0.18 \\
$\mathrm{TiO}_{2}$ & 0 & $<0.01$ & 0.26 \\
$\mathrm{LOI}$ & - & 43.93 & 26.23 \\
\hline
\end{tabular}


Table 1 shows the chemical analysis of Steel Slag, conventional limestone aggregates and Construction and Demolition Wastes which were used.

\section{Granulometry of Aggregates}

Figure 1 shows the granulometry of the aggregates that have been used in this research.

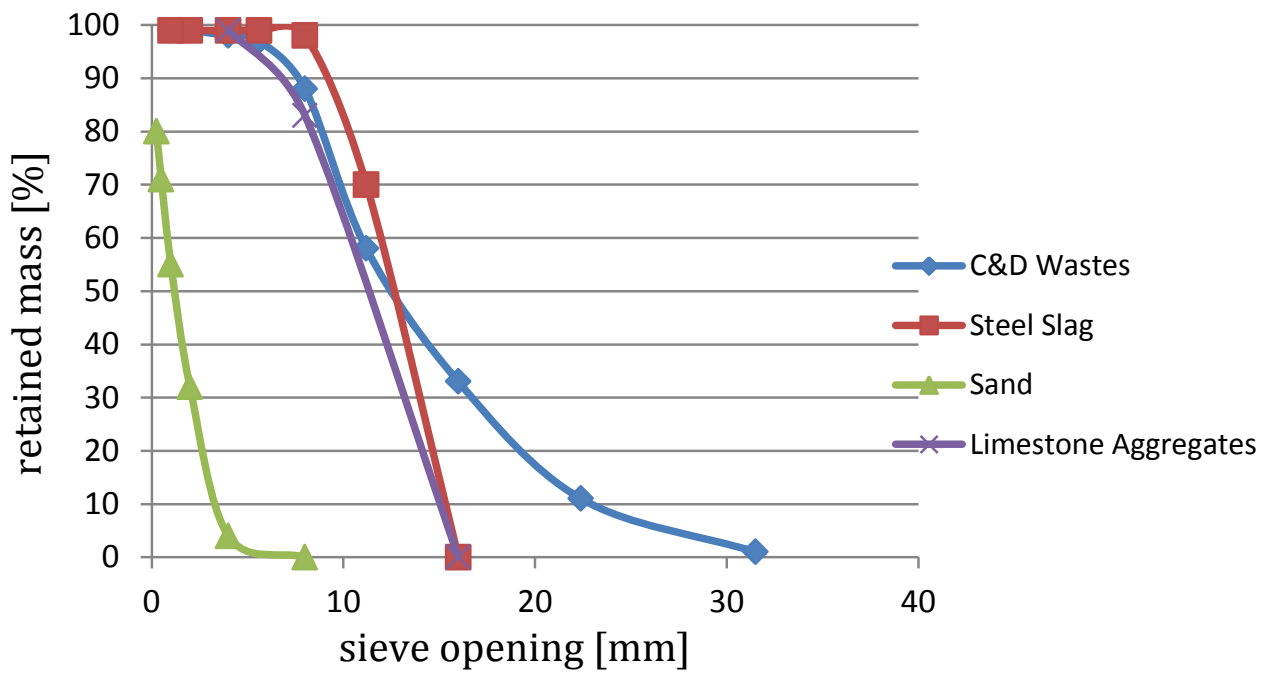

Figure 1. Granulometry of aggregates

\section{Porosimetry Analysis}

Using Nitrogen Porosimetry $\left(\mathrm{N}_{2}\right)$ method the pore size of the aggregates was compared. The results of the surface area and pore size analysis were determined by NOVA 2200e and are shown in Table 2.

Table 2. Surface area and pore size analyses

\begin{tabular}{lccc}
\hline & Steel Slag & Limestone Aggregates & C\&D Wastes \\
\hline Surface Area, $\mathrm{S}_{\mathrm{BET}},\left[\mathrm{m}^{2} / \mathrm{g}\right]$ & 0.724 & 0.406 & 4.850 \\
Pore Volume, $\mathrm{V}_{\mathrm{p}}\left[\mathrm{cm}^{3} / \mathrm{g}\right]$ & 0.003 & 0.001 & 0.013 \\
Average Diameter of Pores, $\mathrm{d}_{\mathrm{p}},[\mathrm{A}]$ & 103.356 & 98.522 & 107.216 \\
\hline
\end{tabular}

\section{Mix Design- Preparation of Samples}

A cement CEM II 42.5 and a laboratory grade sand were used in constant quantities (cement: $171 \mathrm{~kg}$ per $\mathrm{m}^{3}$ of mix and sand: $315 \mathrm{~kg}$ per $\mathrm{m}^{3}$ of mix) in order to produce five types of pervious concrete samples. The first one had 100\% conventional limestone aggregates with, water to cement ratio, w/c: 0.47 (LP: Limestone Pervious). The second had $100 \%$ steel slag aggregates with w/c: 0.58 (SP: Steel slag Pervious). The third one had 50\% limestone and 50\% steel slag aggregates with w/c: 0.53 (LSP: Limestone and Steel slag Pervious). The fourth had 50\% steel slag and 50\% C\&D Wastes with w/c: 0.65 (SCDP*: Steel slag and Construction and Demolition Pervious) and finally the fifth one had all the three types of aggregates 50\% limestone aggregates, 25\% steel slag and 25\% C\&D Wastes with w/c: 0.56 (LSCDP ${ }^{\dagger}$ : Limestone, Steel slag and Construction and Demolition Pervious).

\footnotetext{
${ }^{\dagger} \mathrm{C} \& \mathrm{D}$ Wastes were used on wet base $(\%$ moisture $=4.8)$
} 
Figure 2 shows the granulometry curves of pervious concrete samples.

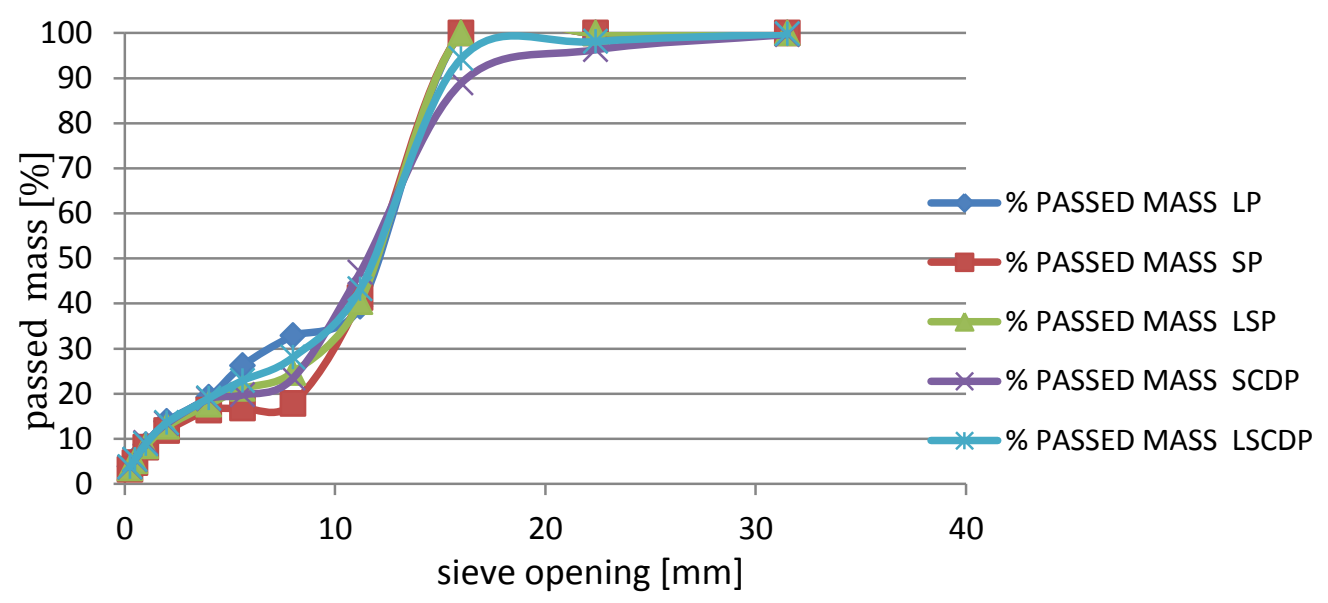

Figure 2. Granulometry curves of pervious concrete samples

\section{Compressive strength}

The produced samples of pervious concrete were measured for their compressive strength according to EN 12390. The results are presented in Figure 3.

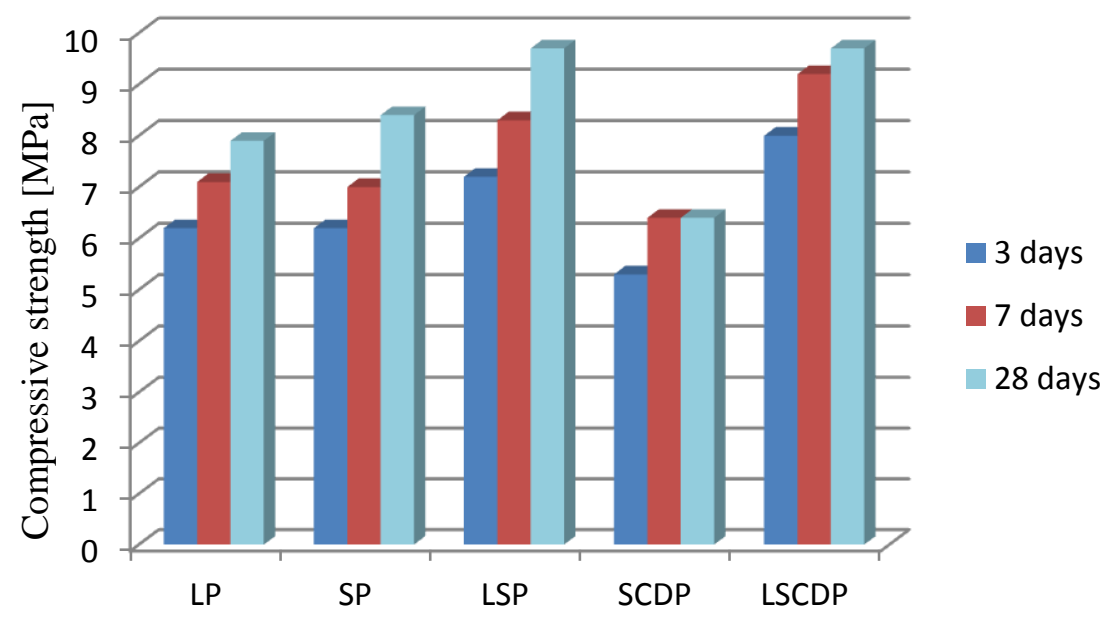

Figure 3. Compressive Strength of Pervious Samples

\section{Water permeability}

Permeability, as a unique ability for water to penetrate through pervious concrete, is expressed in centimetres per second $[\mathrm{cm} / \mathrm{s}]$. Since pervious concrete, generally, possesses a much higher permeability compared to the normal dense concrete, the permeability test method for the latter one was not suitable for testing pervious concrete. As there are no Hellenic, European or American Standards for such testing, a testing method which was similar to the falling head test method for soil "Hellenic standards of soil mechanics laboratory tests E 105-86" was adopted in this research.

Subsequently, the water permeability rate of pervious concrete was calculated by Eq. (1). 


$$
k=\frac{a^{*} L}{A^{*} t} * \ln \left(\frac{h 1}{h 2}\right)
$$

where $k$ is the permeability coefficient $[\mathrm{cm} / \mathrm{s}], a$ is the area of the cylindrical pipe $\left[\mathrm{cm}^{2}\right], A$ is the area of specimen $\left[\mathrm{cm}^{2}\right], L$ is the length of specimen $[\mathrm{cm}], t$ is the time for water to pass from level h1 to h2 [s] through the pipe. The figure below shows the device that has been used.

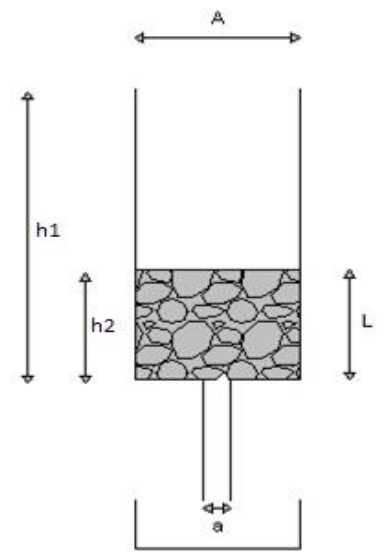

Figure 4.

The results are presented in Table 3.

Table 3. Water Permeability Coefficient $k$

\begin{tabular}{cccccc}
\hline & LP & SP & LSP & SCDP & LSCDP \\
\hline$k,[\mathrm{~cm} / \mathrm{s}]$ & 0.13 & 0.16 & 0.15 & 0.09 & 0.15 \\
\hline
\end{tabular}

\section{Abrasion Behaviour}

The produced samples of pervious concrete were tested for their abrasion behaviour using a Dragster Belt Sander for 1 and 2 minutes respectively and their percentage loss of mass (Figure 5) and their percentage loss of thickness (Figure 6) were measured.

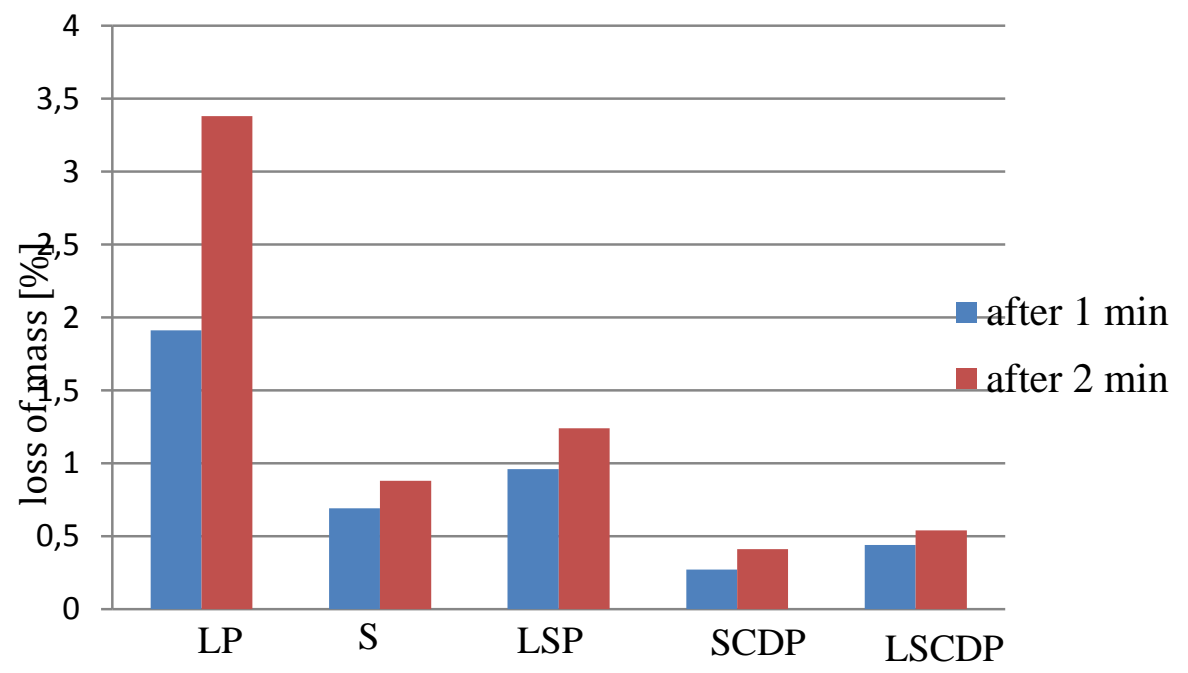

Figure 5. Loss of mass in \% after 1 and 2 minutes respectively 


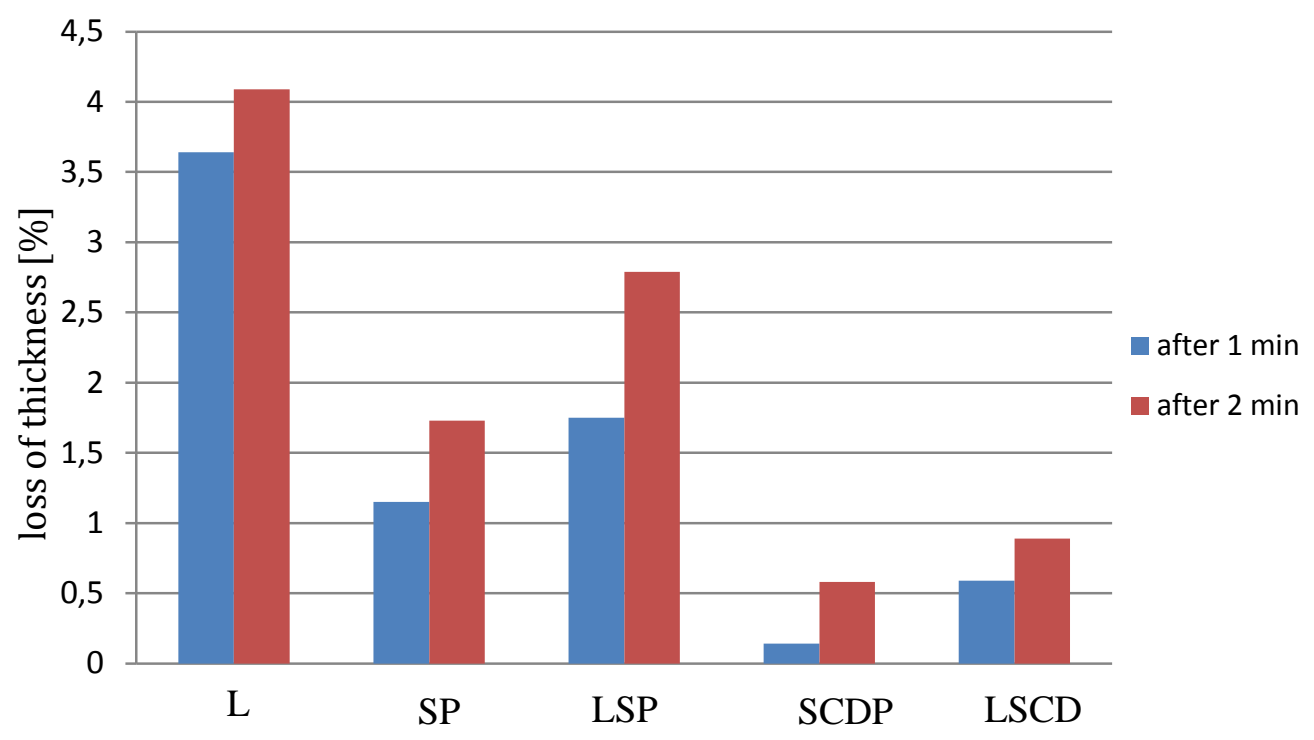

Figure 6. Loss of thickness in \% after 1 and 2 minutes respectively

\section{Porosity Analysis}

Each pervious concrete sample was scanned to produce a 396 slices porosity profile including the entire core depth. The overall processes involved with X-ray CT scanning are shown in Figures 7 and 8. The files of the scanned slices (output raw data) are processed with the program Philips DICOM Viewer R2.6L1-SP1. Finally the images of the slices are processed with the program Image Pro Plus in order to evaluate the percentage of void content.

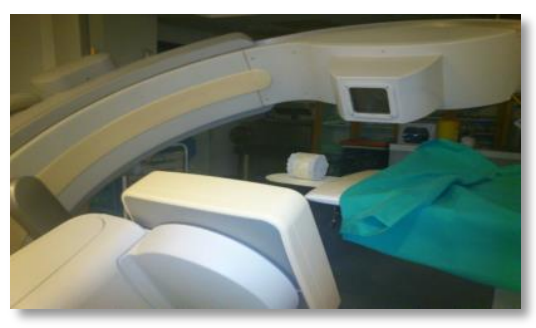

Figure 7. X-ray CT Scan
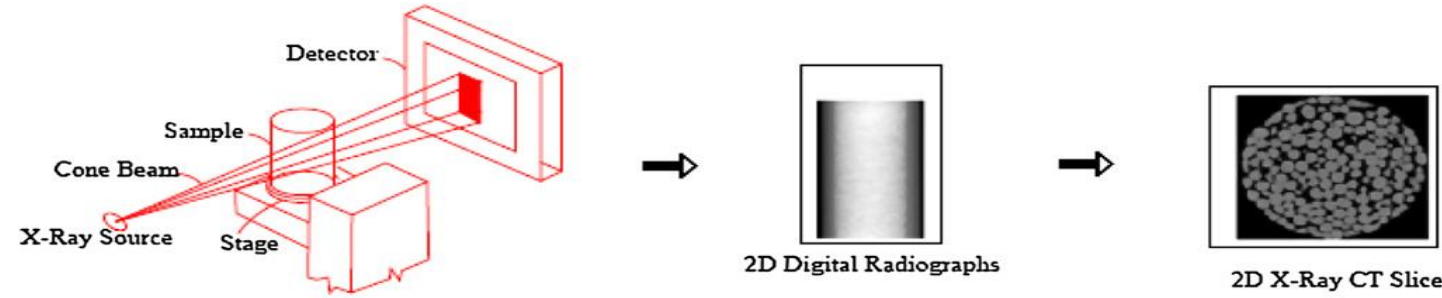

I

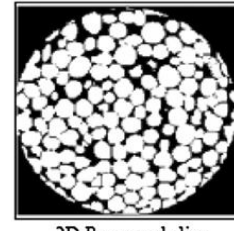

Figure 8. X-ray CT scan 
Some indicative images obtained by X-ray CT Scan are shown below. The black colour represents the voids and the white colour the cement mortar and the aggregates.

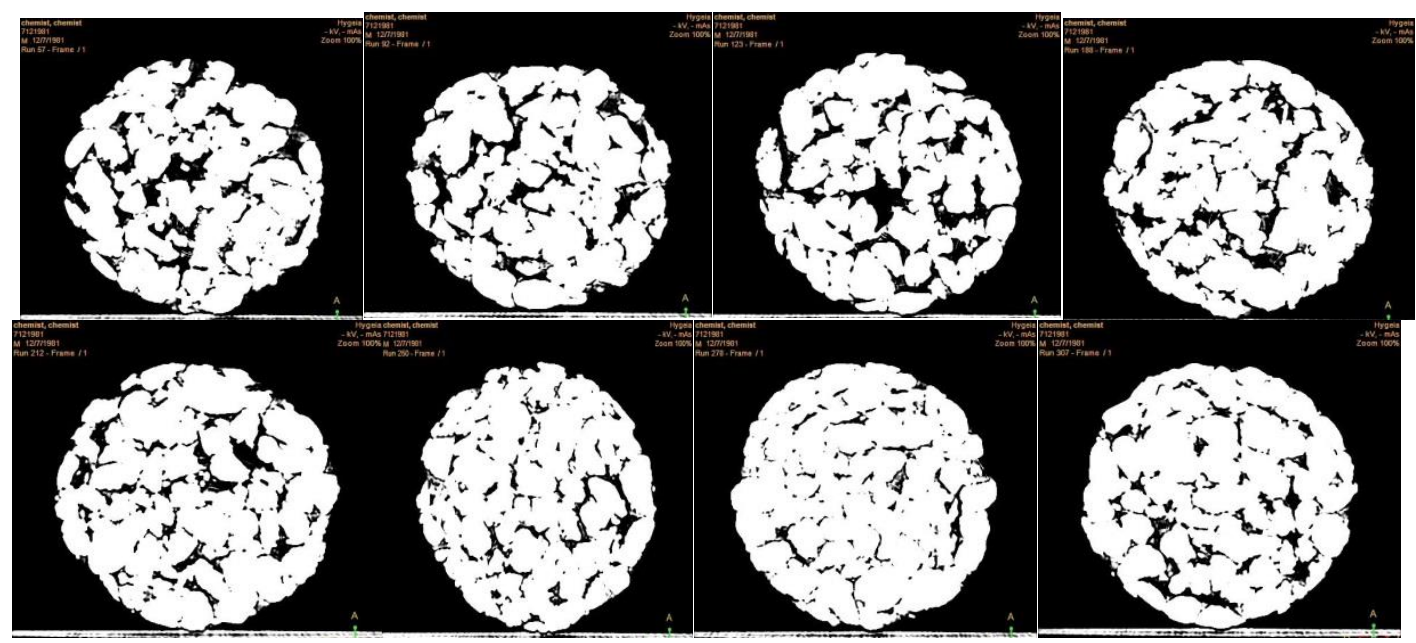

Figure 9. 2D XRay CT Slice of LP

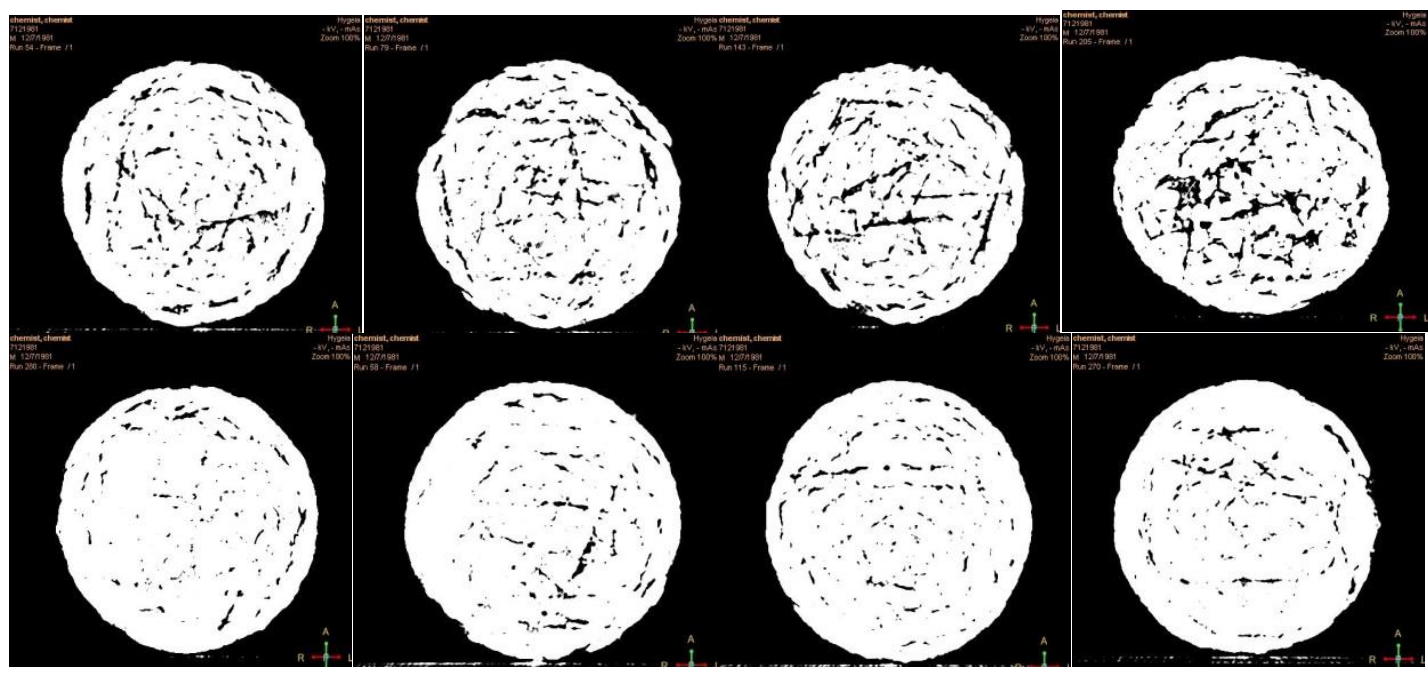

Figure 10. 2D XRay CT Slice of SP

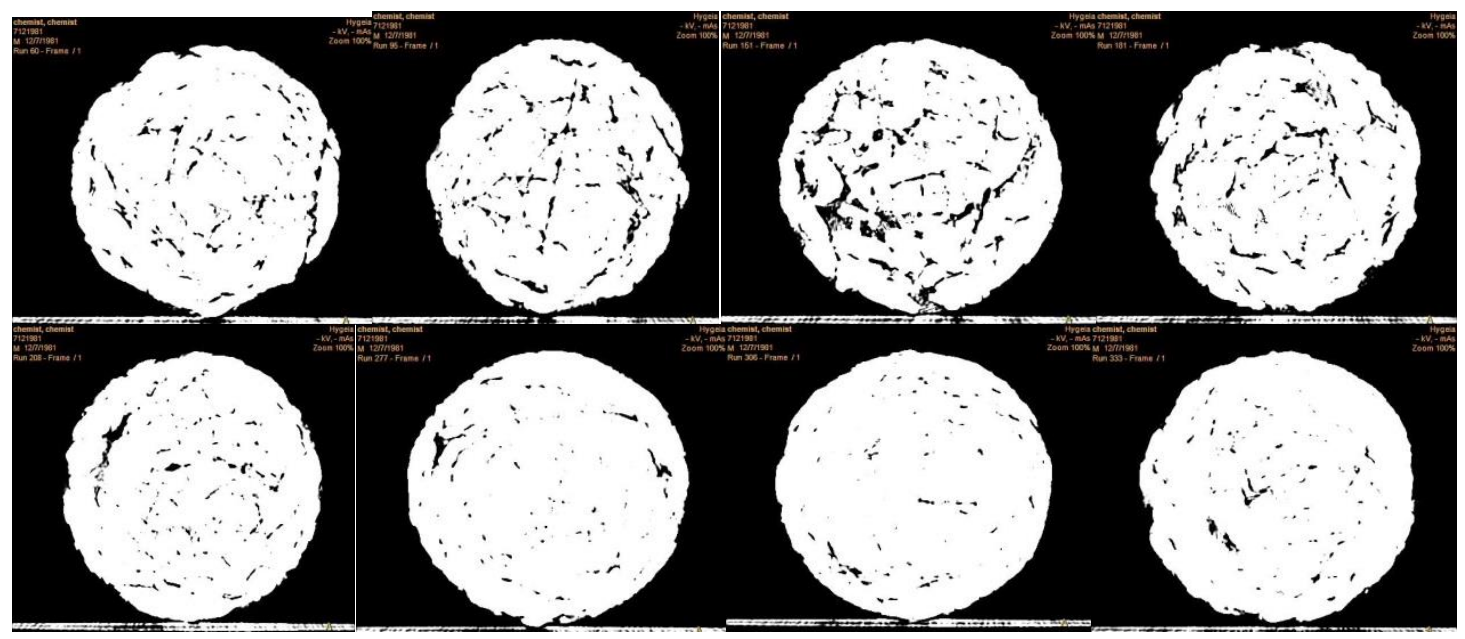

Figure 11. 2D XRay CT Slice of LSP 


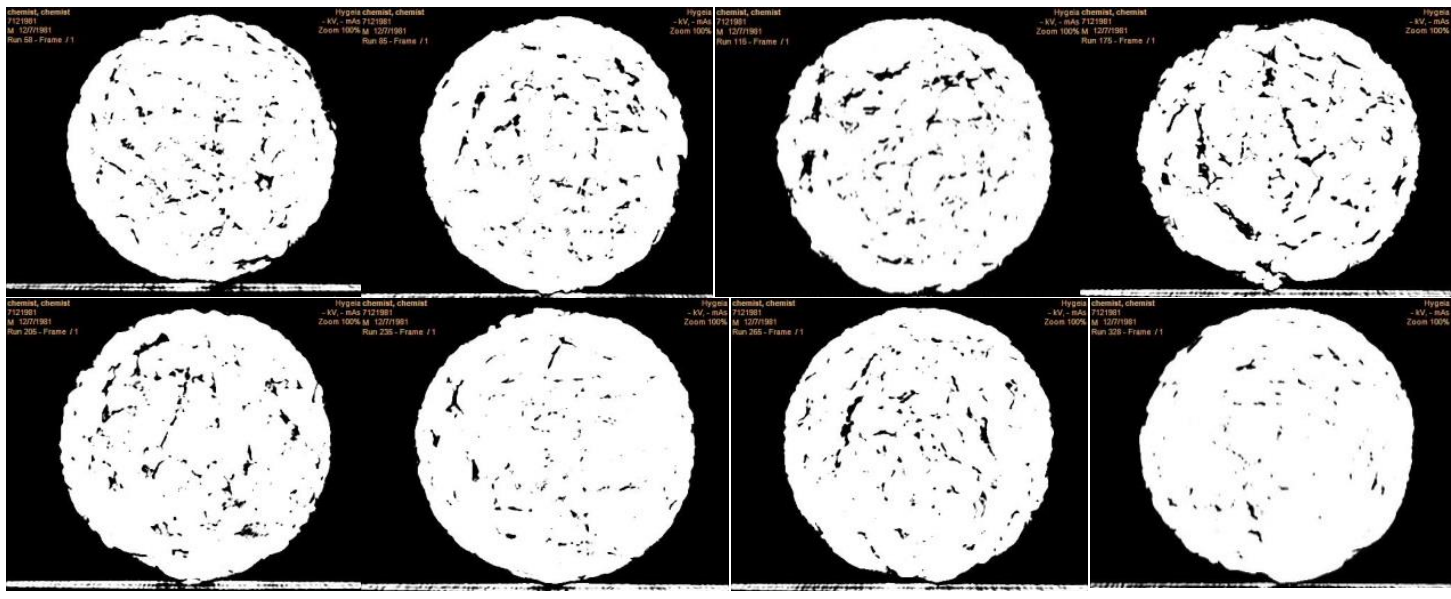

Figure 12. 2D XRay CT Slice of SCDP

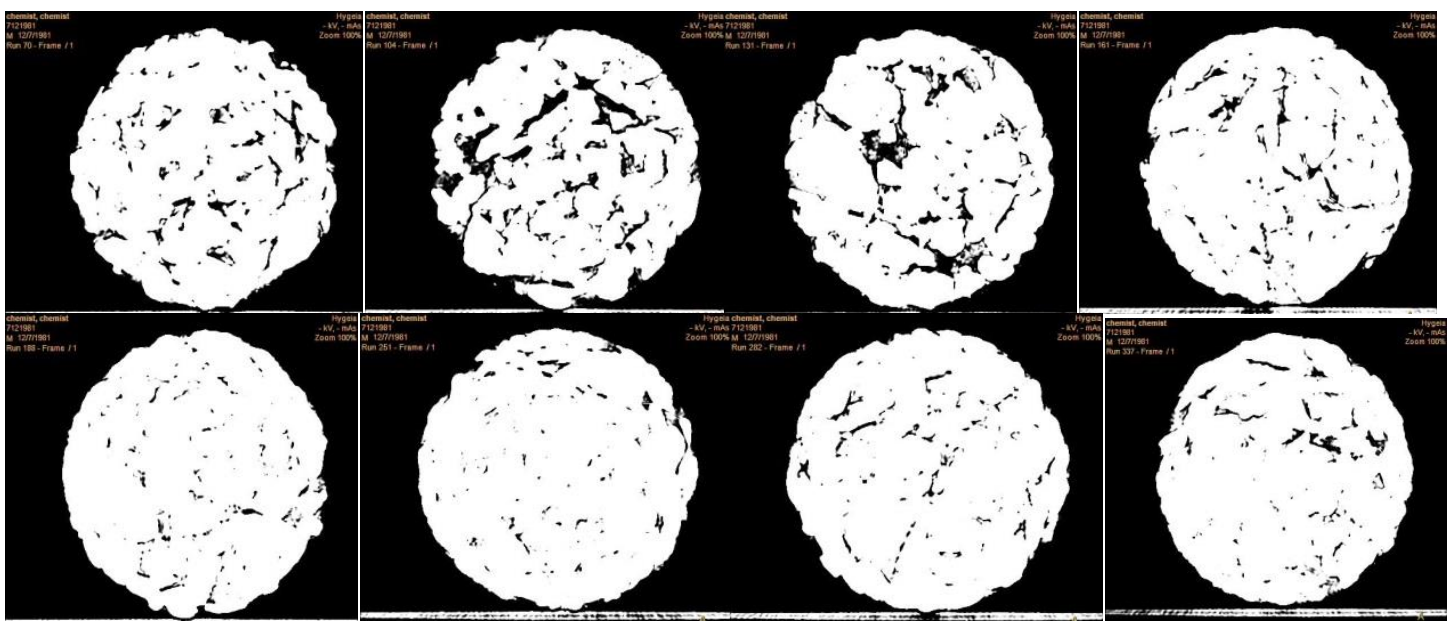

Figure 13. 2D XRay CT Slice of LSCDP

As expected, from Figures 9 to 13 the size and the shape of the pores are seen to depend on the different bonding and packing of the aggregates in all these mix designs.

\section{Percentage of Void Content}

By using the program Image Pro Analysis, the average \% void content of the seven different pervious concrete mix designs was measured. The results are presented in Figure 14 and Table 4.

Table 4. Average Void Content in \%

\begin{tabular}{ccc}
\hline & Void Content [\%] \\
\hline LP & 22.39 \\
SP & 10.23 \\
LSP & 11.17 \\
SCDP & 9.21 \\
LSCDP & 10.72 \\
\hline
\end{tabular}



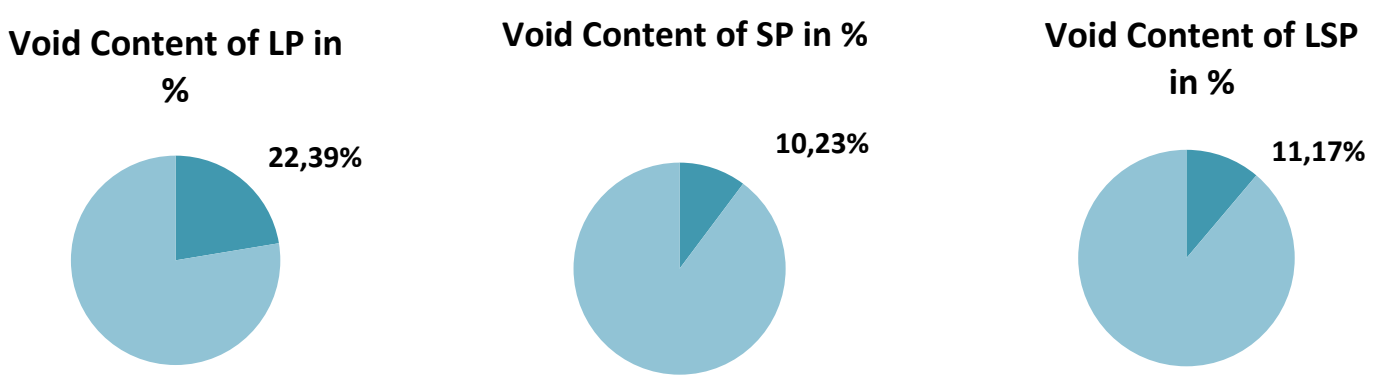

Void Content of SCDP in \%

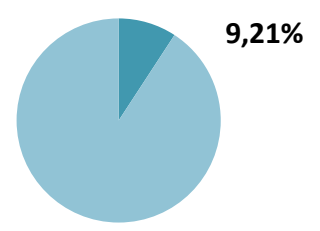

Void Content of LSCDP in \%

$10,72 \%$

Figure 14. Void Content of different samples in \%

\section{RESULTS AND DISCUSSION}

Comparing the results of Table 1 with EN 12620 "Aggregates for concrete" we can observe that the examined materials comply with all their requirements, and can be used as Recycled Concrete Aggregates (RCA). The differences that were observed in the chemical composition were as expected, due to the different nature and characteristics of the materials.

From Figure 1 it is derived that there exists a difference on the granulometry among the various coarse aggregates used in this study. More specifically, the granulometry of steel slag looks more similar to one of the conventional limestone aggregates than to the granulometry of $\mathrm{C} \& \mathrm{~W}$ wastes. It may be noted, for reasons of cost reduction in a possible future application, the alternative aggregates were used as they had been obtained without further grinding. For this reason, as shown below in the mix design, limestone sand has been used as fine aggregate.

The results of the porosimetry analysis (Table 2) are an indication that Steel Slag and $C \& D$ Wastes are more porous materials than limestone aggregates. More specifically, the volume of their pores is 3 and 10 times more than the volume of the limestone pores. Although the high porosity is a disadvantage for the production of the conventional type of concrete, it is the desired quality for pervious concrete. All these indicate that Steel Slag and C\&D Wastes can be proved very promising materials to substitute natural aggregates for producing pervious concrete as they ensure water permeability.

Concerning compressive strength and comparing to conventional limestone aggregates, from Figure 3 it is observed that all the pervious samples have sufficient strength for the range of their intended applications. More specifically, the incorporation of industry by-products or of C\&D Wastes leads to a little superiority of all examined mixtures of aggregates except that of SCDP, which must be attributed to the porous structure of these alternative aggregates.

As far as the water permeability is concerned, and according to the results in Table 3, all pervious concrete samples have a high water permeability coefficient. Additionally it is shown that the samples SP, LSP and LSCDP have an increased permeability than the 
conventional samples of LP. Only the sample of SCDP doesn't present such good behaviour in water permeability; nevertheless its water permeability coefficient is satisfactory for the range of its applications.

Finally, according to the abrasion behaviour (Figures 5 and 6), it is observed that the incorporation of industrial by-products or of $C \& D$ Wastes leads to a significant reduction of abrasion which must be attributed to the better bonding and packing between the aggregates and the cement mortar in these pervious concrete samples.

According to Table 4 it is observed that the active porosity of the several pervious concrete samples depends on the aggregates that have been used for the production of these compositions. More specifically, the addition of steel slag leads to a less porous pervious concrete material. This can be explained by the geometrical characteristics and the particle size of steel slag which leads to a more dense structure and enables the mortar paste to bond more easily. On the contrary, the use of coarse aggregates (for example C\&D Wastes) creates a more porous structure in the examined samples. The larger pores of the pervious samples with C\&D Wastes and conventional limestone aggregates create several paths which enable the water to pass through.

\section{CONCLUSIONS}

According to the above results, all the pervious samples that have been produced have satisfactory water permeability and sufficient strength for the range of their intended applications. More specifically:

- Relating to the abrasion behaviour, it is observed that the incorporation of industry by-products or of $\mathrm{C} \& \mathrm{D}$ Wastes leads to a significant reduction of the abrasion;

- The coexistence of the three different granulometry curves of aggregates in the LSCDP sample leads to a more dense structure which enables the mortar paste to bond more easily. That is why LSCDP shows high compressive and tensile strength and better abrasion behaviour, with no adverse effect in the water permeability;

- The samples SP, LSP and LSCDP are more water permeable than LP. That can be explained by the high porosity of Steel Slag and C\&D Wastes in contrast with the porosity of the limestone aggregates;

- As far as the use of C\&D Wastes is concerned, and more specifically, according to the sample SCDP, we can observe that the incorporation of a high percentage of $C \& D$ Wastes leads to a reduction in compressive strength, tensile strength and water permeability;

- According to the granulometry curves of pervious concrete samples (Figure 2), no significant difference of the curves can be observed; so the difference in the properties of the produced pervious concrete samples could be attributed to the high porosity of the recycled aggregates: Steel Slag and C\&D Wastes;

- According to the porosity analysis, it is observed that the active porosity of the several pervious concrete samples depends on the aggregates that have been used for the production of these compositions. The use of coarse aggregates leads to a pervious product with a more porous structure. On the contrary, the more spherical aggregates create a more dense structure with less percentage of void content;

- A very important factor for the active porosity of pervious concrete samples is the proper compaction. A proper compaction, according to ACI 522R-06, creates open porous structures with constant percentage of void content in all 
layers of pervious concrete. That is a desirable quality because it allows water to drain through and it ensures the sustainable role of this product.

\section{ACKNOWLEDGMENT}

This research has been co-financed by the European Union (European Social Fund ESF) and Greek national funds through the Operational Program "Education and Lifelong Learning" of the National Strategic Reference Framework (NSRF) - Research Funding Program: Heracleitus II. Investing in knowledge society through the European Social Fund.

\section{REFERENCES}

1. ACI Committee, 522R-06: "Pervious Concrete" Technical Documents, 2006

2. ACI Committee, 522.1-08: "Specification for Pervious Concrete Pavement" Technical Documents, 2008

3. Sparkman, A., "Why Pervious Concrete?" Tennessee Concrete, Winter, 2001

4. Bentz, D.P., "Virtual Pervious Concrete: Microstructure, Percolation, and Permeability" Materials Journal, Volume 105, Issue 3, pp 297-301, 2008

5. Haselbach, L., Freeman R., "Vertical Porosity Distributions in Pervious Concrete Pavement", Materials Journal, Volume 103, Issue 6, pages 452-458, 2006

6. Vardaka, G., Galbenis C-T., Tsimas S., "Evaluation of Construction and Demolition Wastes as Aggregates in Pervious Concrete", Second International Conference on Sustainable Construction Materials and Technologies, Ancona, Italy, Proceedings of specials sessions pp: 221-225, 28-30 June 2010

7. Katz, A., " Properties of concrete made with recycled aggregate from partially hydrated old concrete" Cement and Concrete Research, Vol. 33, pp. 703-711, 2003, http://dx.doi.org/10.1016/S0008-8846(02)01033-5

8. Ryu, J.S., "Improvement on strength and impermeability of recycled concrete made from crushed concrete coarse aggregate" Materials Science Letter, Vol. 21, pp. 1565-1567, 2002, http://dx.doi.org/10.1023/A:1020349011716

9. Ryu, J.S., "An experimental study on the effect of recycled aggregate concrete properties" Magazine of Concrete Research, Vol. 54, pp. 7-12, 2002, http://dx.doi.org/10.1680/macr.2002.54.1.7

10. Maslehuddin, M., Sharif A.M., Shameem M., Ibrahim M., Barry M.S., "Comparison of properties of steel slag and crushed limestone aggregate concretes", Construction and Building Materials 17, pp 105-112, 2003, http://dx.doi.org/10.1016/S0950-0618(02)00095-8

11. Haselbach, L., Freeman, R., "Vertical Porosity Distributions in Pervious Concrete Pavement", Materials Journal, Volume 103, Issue 6, pp 452-458, 2006

12. Delatte, N., Schwartz, S., "Sustainability Benefits of Pervious Concrete", Second International Conference on Sustainable Construction Materials and Technologies, Ancona, Italy, 28-30 June 2010 